\title{
Management of the River Vedi Annual Runoff
}

\section{Varduhi Margaryan ${ }^{1, *}$, Ksenia Raevich ${ }^{2}$}

${ }^{1}$ Yerevan State University, Department of Physical Geography and Hydrometeorology, Faculty of Geography and Geology, 0025 Alek Manoukian 1 Street, Yerevan, Armenia.

${ }^{2}$ Siberian Federal University, Institute of Space and Information Technologies, Chair of Systems of Artificial Intelligence, 660074 Kirenskogo St. 26, Krasnoyarsk, Russia.

\begin{abstract}
The article presents the following tasks for the Vedi river: to study and analyze the main physical and geographical factors determining the runoff; to collect, work out, analyze and estimate the results of factual hydro-meteorological observations of the river basin; to discover and analyze the features of intra-year distribution of the river runoff basin; to study dynamic changes of the river runoff; to create the methods of long-term forecasting of monthly and annual runoff; to create a map of spatial distribution of the river runoff. For these purposes were used the data of hydrological and meteorological stations, points of basin observations and mathematical-statistic, geographic, mapping, analytical and correlation methods.
\end{abstract}

\section{Introduction}

The Vedi river is the left tributary of the Araks, Fig. 1. The Vedi river basin is located on $800-2800 \mathrm{~m}$ height of Armenian volcanic plateu: the average sea level height is $2090 \mathrm{~m}$. The length of the river is $58 \mathrm{~km}$, up to Urtsadzor -29 $\mathrm{km}$, the square is accordingly 633 and $329 \mathrm{~km} 2$ in Table 1.

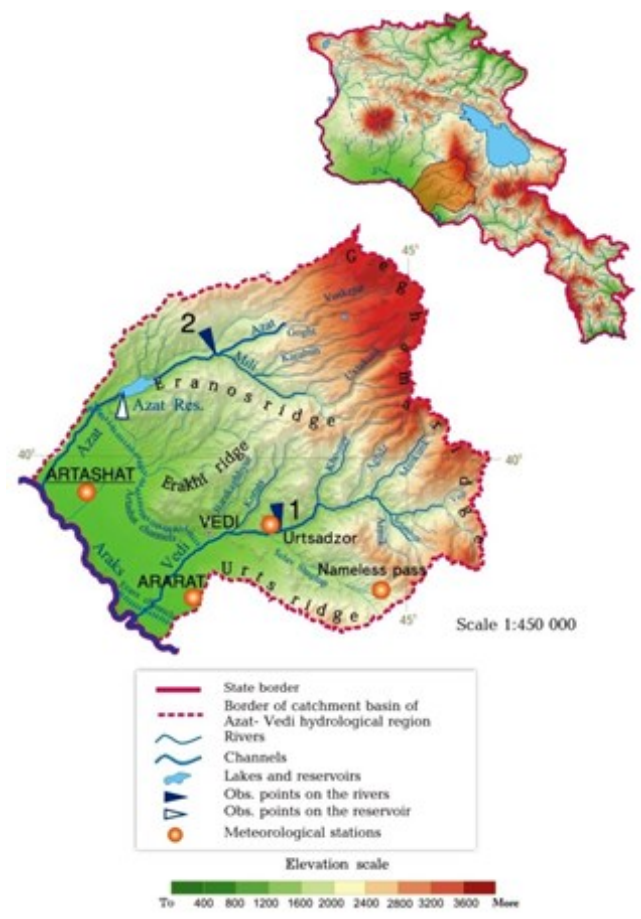

Fig. 1. The position of the Vedi catchment basin in the Azat-Vedi hydrological region 1-the r. Vedi - p. Urtsadzor; 2-the r. Azat- p. Garni

*Corresponding author: vmargaryan@ysu.am 
Table 1. The main metrical characteristics of the Vedi river

\begin{tabular}{|l|c|c|c|c|c|c|}
\hline \multirow{2}{*}{\multicolumn{1}{c}{ River - point }} & \multicolumn{2}{|c|}{ From, $\mathrm{km}$} & \multicolumn{2}{c|}{ River inclination, \%o } & \multicolumn{2}{c|}{ Catchment square } \\
\cline { 2 - 7 } & lade & $\begin{array}{c}\text { sourc } \\
\mathrm{e}\end{array}$ & average & $\begin{array}{c}\text { average } \\
\text { balanced }\end{array}$ & $\begin{array}{c}\text { square, } \\
\mathrm{km}^{2}\end{array}$ & $\begin{array}{c}\text { average } \\
\text { balanced } \\
\text { height }\end{array}$ \\
\hline The Vedi - v. Azizkend & 39 & 20 & 66 & 60 & 142 & 2240 \\
\hline The Vedi - v. Urtsadzor & 29 & 30 & 54 & 48 & 329 & 2090 \\
\hline The Vedi - v. Chimankend & 25 & 33 & 51 & 45 & 348 & 2060 \\
\hline $\begin{array}{l}\text { The SelavShahaplu - v. } \\
\text { Shahaplu }\end{array}$ & 10 & - & - & - & 59.0 & - \\
\hline The Kyusuz - v. Kyusuz & 1,5 & 14 & 108 & 102 & 50.0 & 2260 \\
\hline The Akhsy - the lade & 0,3 & 16 & 109 & 104 & 25.0 & 2020 \\
\hline $\begin{array}{l}\text { The Khosrov - the pioneer } \\
\text { camp }\end{array}$ & 8,0 & 9,0 & 149 & 153 & 26.0 & 1980 \\
\hline
\end{tabular}

The waters of the river are completely used for irrigation in the middle and lower flows. Therefore, the main significance lies in the studying of features of intra-year distribution of the river runoff, the estimation and management of the river runoff.

\section{Tasks and solution methods}

Taking into account all the above-mentioned, the following tasks have been solved:

- $\quad$ to study and analyze the main physical and geographical factors determining the runoff;

- $\quad$ to collect, work out, analyze and estimate the results of factual hydro-meteorological observations of the river

basin;

- $\quad$ to discover and analyze the features of intra-year distribution of the river runoff basin;

- $\quad$ to study dynamic changes of the river runoff;

- $\quad$ to create the methods of long-term forecasting of monthly and annual runoff;

- $\quad$ to create a map of spatial distribution of the river runoff.

For these purposes the data of hydrological and meteorological stations and points of basin observations were collected, worked out and analyzed, which were kept in Armstatehydromet and used according to literary sources [1-5] and mathematical-statistic, geographic, mapping, analytical and correlation methods.

Flow formation is affected by permanently changeable meteorological factors and permanent physical and geographical factors. The features and regularities of the river runoff distribution are conditioned by the influence of physical and geographical factors. The main physical and geographical factors, which determine the characteristic of the river runoff formation, are geographical location, relief, geological and hydro-geological structure, climate and soilvegetation cover of this area.

In the basin, the hydrological studies have been made since the 30 s of 20 th century. In the period of the study (1928 - 2009) 6 hydrological points worked in the basin, 4 of them worked only for one year (1968), and 1 of them for four years $(1960$ - 1963). There is only the Vedi river at the Urtsadzor hydrological point that is still working in the long series of observations. Although these observations started in 1928, the results of the observations have been kept since 1937, therefore, the data of 1937-2009 are used in the work. During its activity, the Urtsadzor hydrological point changed its former location several times: its catchment square, discontinuity of water level data. However, as the research found out, flows didn't have essential changes at the hydrological point in this period. Therefore, it is possible to use the results of water flow observations of 1937-2009 for forecasting and characterization of water regime basin.

In contrast to hydrological research in the basin, the meteorological researches have started later specifically since 1949. However, it should be noted that according to the continuity and homogeneity of meteorological observations the basin is one of the worst assimilated areas for forecasting. From the point of the river runoff assessment, the meteorological stations and points, which have rather long and reliable-sequence of data, are absent in the hydrological forecasts in the main zone of the stream flow formation. Thus, the data from the meteorological observations of stations in neighboring areas that have a relatively long data sequence are used to obtain forecast connections. It was found out that, when using the Artashat data, particularly good results are obtained for reconstructing the sequence of observational data at the Urzadzor and Ararat stations. They have got close correlations. However, using these data in forecast connections does not provide good results. Therefore, we used the actual data of observations from Artashat station in the work.

From the point of the river irrigation for the estimation of the river runoff, the important characteristic is intra-year runoff distribution by months and seasons of the year (table 2). It means, in terms of the water use, the intra-year runoff distribution and the water regime of rivers are important characteristics that depend on sources of supply and conditions of runoff generation and formation. The feeding source of any river plays an important role for intra-year runoff distribution and water regime. As the other rivers of the republic, the Vedialso river is fed with melted, rainy and underground water, which means that the Vedi river has the mixed feeding. In case of these conditions the Vedi river 
has an unstable water regime (large level fluctuations). For the river of Armenia, the Vedi river is also characterized with spring-summer floods, summer-autumn and winter stages of a low water level. As the other rivers of the Araks basin, the autumn-winter runoff of the Vedi river exceeds the summer-autumn runoff.

Table 2. Intra- year and seasonal distribution of long-term average values of runoff consumption vs. annual ones (\%)

\begin{tabular}{|c|c|c|c|c|c|c|c|c|c|c|c|c|c|c|c|}
\hline \multirow[b]{2}{*}{ River - point } & \multicolumn{12}{|c|}{ Months } & \multicolumn{3}{|c|}{ Seasonal } \\
\hline & I & II & III & IV & $\mathrm{V}$ & VI & VII & VIII & IX & $X$ & XI & XII & $\begin{array}{l}5 \\
\geq\end{array}$ & $\begin{array}{l}\underset{a}{2} \\
\stackrel{1}{z}\end{array}$ & $\begin{array}{l}\Xi \\
\dot{x}\end{array}$ \\
\hline The r. Vedi - p. Urtsadzor & 4 & 4 & 6 & 20 & 36 & 13 & 4 & 2 & 2 & 3 & 4 & 3 & 69 & 77 & 23 \\
\hline $\begin{array}{l}\text { The r. SelavShahap - p. } \\
\text { Shahap }\end{array}$ & 2 & 6 & 9 & 24 & 24 & 16 & 3 & 5 & 1 & 3 & 3 & 2 & 64 & 74 & 26 \\
\hline
\end{tabular}

The annual runoff of the basin is characterized with one spring maximum (April-June). Moreover, a slight increase in consumption is observed during the autumn rains (fig. 2). However, it is important to note that the average monthly values of consumption during the spring flood can be 5-10 times more than the average annual values. In a low water level period the lowest monthly average values of consumption are 10-30\% from the average annual values. Even the drying of the river is sometimes observed and therefore it needs irrigation.

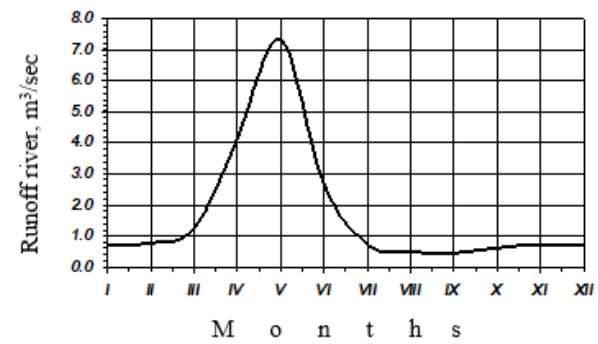

Fig. 2. Annual course of average values of runoff of the Vedi river at the Urtsadzor hydrological point

In intra-year runoff distribution, there is also some difference between cold and warm seasons of the year. In the warm period (IV-X), the Vedi river passes $80 \%$ of the total annual runoff and in the cold period (XI-III) - $20 \%$.

The average annual consumption according to the long-term at Urtsadzor hydrological point is $1,71 \mathrm{~m} 3 / \mathrm{sec}$. The maximum of the annual average value was observed in 1946 as 3,38 m3/sec while the minimum observed in 2004 was $0,37 \mathrm{~m} 3 / \mathrm{sec}$. From March the increase in water outlet is observed, which reaches to the maximum in May and beginning from June water outlets decrease almost in 2-3 times more and reach to the minimum in August-September.

During the year, runoff distribution increases the influence on the human economic activity more and more and therefore violates the natural state of water objects, consequently the runoff redistribution is observed. The water is taken from the river during the warm period for water supply purposes. Therefore, due to the intensive irrigation, water production is likely to decrease from July, and it is only $8 \%$ of the average annual volume in the period from July to September. However, natural runoff was not restored in the article.

After the floods there is a long-term shortage of water period with summer-autumn and winter stages in the river. In this stage the river is mainly fed with underground water and in winter it is fully fed like this. Nevertheless, the stage of water shortage sometimes $(1965,1979,1982,1989)$ observes disturbance in the summer-autumn periods because of floods after heavy showers. The least amount of water (once the river is not passed with the runoff and it becomes a dry hollow) is observed in the second part of summer unlike general regularity of runoff of the water period shortage in Armenia. It is conditioned by the anthropogenic factors due to the water supply point from the river, and as a result, it decreases the natural runoff of rivers. The average water supply point is $0,15-0,70 \mathrm{~m} 3 / \mathrm{sec}$.

As it can be seen, the river basin is characterized with unequal distribution of river runoff during the year. Therefore, it is necessary to organize correct regulation and management of the river runoff for economic productive water use of the river. The role of it increases more in conditions of climate change depending on dynamic change of the river runoff.

The scientific knowledge is necessary for more productive organization of regulation and management of runoff, which means, it should be forecasted. Thus, after studying, analyzing and estimation of physical and geographical conditions of the river basin, the literary sources have become the methods for long-term forecasting of monthly and annual runoffs. The monthly forecast is published on the 23-24 of the previous month.

After studying and analyzing of physical and geographical conditions, existing literary sources and initial materials have received some forecast dependencies, which can be applied during operational forecasting and consultation.

Stable winter regime makes it possible to establish a close connection between runoff values of neighboring months (previous and next). These dependencies are closely related and can be used for the forecasts of water runoff shortage. For the runoff forecast in January $\left(\bar{Q}_{I}\right)$ and February $\left(\bar{Q}_{I I}\right)$ we obtained the following correlation equations: 


$$
\begin{aligned}
& \bar{Q}_{I}=0.90 \bar{Q}_{X I I}+0.12 \\
& \bar{Q}_{I I}=0.90 \bar{Q}_{I}+0.13 \\
& \bar{Q}_{I I}=0.66 \bar{Q}_{X I I}+0.28 \bar{Q}_{I}+0.02
\end{aligned}
$$

In March, the water content is formed due to melting and underground runoff. The runoff in March $\left(\bar{Q}_{I I}\right)$ is conditioned by the water content in the previous period and the autumn-winter moistening level of the soil, which is expressed by the amount of precipitations.

The forecast connections are based on the average monthly outlet values in January and February $\left(\left(\bar{Q}_{I}, \bar{Q}_{I I}\right)\right)$ at Urtsadzor hydrological point and precipitation values from October to February at Artashat $\left(\sum X_{X-I I}\right)$ meteorological station.

$$
\bar{Q}_{I I I}=0.78 \bar{Q}_{I}+0.51 \bar{Q}_{I I}+0.003 \sum X_{X-I I}-0.04
$$

April, May and June are the months of flood period and they are relatively difficult to forecast. A large role in runoff formation is devoted to precipitations in the winter period, the amount of liquid precipitations of the flood period, the average air temperature, the summary of positive temperatures, and the runoff of the preceding period.

In April, the forecast connections are based on the average monthly outlet values in January, February and March at Urtsadzor hydrological point $\left(\bar{Q}_{I}, \bar{Q}_{I I}, \bar{Q}_{I I I}\right)$, precipitations of October-December period at Artashat meteorological station $\left(\sum X_{X-X I I}\right)$, air temperature in April $\left(\bar{t}_{I V}\right)$, air moisture deficit in March $\left(\bar{d}_{I I I}\right)$.

$$
\bar{Q}_{I V}=1.11 \bar{Q}_{I I I}+2.58 \bar{Q}_{I I}-1.38 \bar{Q}_{I}+0.02 \sum X_{X-X I I}+0.30 \bar{t}_{I V}-0.26 \bar{d}_{I I I}-2.27
$$

In May, as a rule, the main part of the annual runoff ( $35 \%)$ flows out of the river. The water content in May is mainly formed with melting and partly with rainy waters. The average air temperature in April and the amount of precipitations within the preceding period were taken as the major indices, which characterize the residual moisture supply in the river basin.

The forecast connections are based on the average monthly runoff in March and April $\left(\bar{Q}_{I I}, \bar{Q}_{I V}\right)$, which are the absolute maximum, and the average air temperature in April at Artashat meteorological station $\left(t_{\max _{I V}}, \bar{t}_{I V}\right)$ :

$$
\bar{Q}_{V}=1.11 \bar{Q}_{I V}+1.12 Q_{I I I}-0.27 t_{\max _{I V}}-0.97 \bar{t}_{I V}+20.9
$$

In June, the forecast connections are based on the following values: the average monthly outlet in May $\left(\bar{Q}_{V}\right)$ at Urtsadzor hydrological point, the average monthly and absolute maximum temperatures $\left(\bar{t}_{V}, t_{V \max }\right)$, atmospheric precipitations in June $\left(X_{V I}\right)$ at Artashat meteorological station:

$$
\bar{Q}_{V I}=0.36 \bar{Q}_{V}-0.57 \bar{t}_{V}-0.22 t_{V \max }+0.01 X_{V I}+16.3
$$

In July, the runoff is formed mainly due to underground water. Since the first decade of July the stage of water shortage is formed in the river. The precipitations, which fell on dry soil, did not flow into the river. Only in some years there was some increase of runoff when a large amount of precipitations fell on wet soil. The forecast connections are based on the average monthly values of outlet in June $\left(\bar{Q}_{V I}\right)$ and air temperature in June $\left(\bar{t}_{V I}\right)$ at Artashat meteorological station:

$$
\begin{aligned}
& \bar{Q}_{V I I}=0.19 \bar{Q}_{V I}+0.21 \\
& \bar{Q}_{V I I}=0.16 \bar{Q}_{V I}-0.08 \bar{t}_{V I}+2.09
\end{aligned}
$$

In August,in general, the runoff is formed due to the underground runoff component. The forecast connections are based on the average monthly values of runoff in July $\left(\bar{Q}_{V I I}\right)$,air humidity deficit $\left(\bar{d}_{V I I}\right)$ and wind speed $\left(\bar{V}_{V I I}\right)$ in July:

$$
\begin{aligned}
& \bar{Q}_{V I I I}=0.48 \bar{Q}_{V I I}+0.08 \\
& \bar{Q}_{V I I I}=0.41 \bar{Q}_{V I I}-0.02 \bar{d}_{V I I}+0.12 \bar{V}_{V I I}+0.39
\end{aligned}
$$

In September the runoff is formed due to the underground runoff component. The forecast connections are based on the values of outlet in August $\left(\bar{Q}_{V I I I}\right)$ and the average monthly wind speed in August $\left(\bar{V}_{V I I I}\right)$ at Artashat:

$$
\begin{aligned}
& \bar{Q}_{I X}=0.79 \bar{Q}_{V I I I}+0.07 \\
& \bar{Q}_{I X}=0.64 \bar{Q}_{V I I I}+0.15 \bar{V}_{V I I I}+0.02
\end{aligned}
$$

In October the second maximum of precipitations is observed in the basin: its amount almost doubles compared to the amount of summer precipitations. 
The forecast connections are based on the values of the average monthly outlets in August and September $\left(\bar{Q}_{V I I I}\right.$, $\left.\bar{Q}_{I X}\right)$, the air temperature in September at Artashat $\left(\bar{t}_{I X}\right)$, the average monthly wind speed $\left(\bar{V}_{I X}\right)$ and the precipitations in October $\left(X_{X}\right)$ :

$$
\begin{aligned}
\bar{Q}_{X}= & 0.17 \bar{Q}_{V I I I}+0.55 \bar{Q}_{I X}-0.04 \bar{t}_{I X}+0.10 \bar{V}_{I X}+0.01 X_{X}+0.82 \\
\bar{Q}_{X}= & 0.69 \bar{Q}_{I X}-0.03 \bar{t}_{I X}+0.01 X_{X}+0.11 \bar{V}_{I X}+0.69 \\
& \bar{Q}_{X}=0.81 \bar{Q}_{I X}+0.21
\end{aligned}
$$

In November and December, the water content in the river is mainly formed due to the underground runoff.

The forecast connections are based on the values of the average outlet values in $\operatorname{October}\left(\bar{Q}_{X}\right)$ :

$$
\bar{Q}_{X I}=0.95 \bar{Q}_{X}-0.15
$$

In December, the water content in the river is formed due to the underground runoff.

The forecast connections are based on the values of the average monthly outlet values in October and November $\left(\bar{Q}_{X}, \bar{Q}_{X I}\right)$, the air humidity deficit in November $\left(\bar{d}_{X I}\right)$ at Artashat:

$$
\begin{aligned}
& \bar{Q}_{X I I}=0,77 \bar{Q}_{X I}+0,16 \\
& \bar{Q}_{X I I}=0,06 \bar{Q}_{X}+0,72 \bar{Q}_{X I}+0,15 \\
& \bar{Q}_{X I I}=0,06 \bar{Q}_{X}+0,75 \bar{Q}_{X I}+0,03 \bar{d}_{X I}+0,05
\end{aligned}
$$

\section{Conclusion}

Thus, we can observe the tendency of the river runoff reduction, especially since the 70 s of XX century. It observes both of annual and maximum runoff.

There is a noticeable shortage of water period in the river with summer-autumn and winter periods: the minimum outlet of water is mainly observed in summer, which is conditioned by water supply points.

In the period of spring floods, the river passes $65-70 \%$ of annual runoff. Moreover, the maximum expense of river water is often observed at this time. It usually occurs in April and in early May, but especially in the first half of May.

The forecasting methods, which were created as a result of the research, can be used for operational forecasting, and the river runoff can be managed with the help of the predicted values made in advance. We suggest accumulating water during the high water season for using it in a region with a low water level.

Practical estimation of hydrological forecasts, first of all, is determined by its accuracy and execution time. Therefore, in order to organize the hydrological service of that or another economic object, first of all, it is necessary to take into account the demand for time and forecast accuracy and find the optimal ratios between these two indices based on forecast possibilities of a particular hydrological phenomenon of a certain river basin.

\section{References}

1. Margaryan V.G. The Features of Formation of Araks Basins Rivers Runoff (in Armenia) and Regularities of Spatio-Temporal Distribution. Abstracts of the ISARM2010 International Conference "Transboundary, Aquifers Challenges and New Directions", Paris, France, 2010, p.173.

2. Margaryan V.G. The Features of Formation of Araks Basins Rivers Runoff (in Armenia) and Regularities of Spatio-Temporal Distribution. Abstracts of the ISARM2010 International Conference "Transboundary, Aquifers Challenges and New Directions", CD- ROM, Paris, France, 2010.

3. Margaryan V.G. The management of runoff of river Vedi based on long-term monthly forecasts. / Sovremennye problemy vodokhranilishh i ikh vodosborov. Gidro- i geodinamicheskie processy. Upravlenie vodnymi resursami. [Current problems of reservoirs and their water basins. Hydro- and geodynamic processes. Management of water resources], Mezhdunarodnaya nauchno-prakticheskaya konferenciya "Sovremennye problemy vodokhranilishh i ikh vodosborov" (29 - 31 May, 2015, Perm): in 2 volumes, Vol.1: Gidro- i geodinamicheskie processy. Upravlenie vodnymi resursami. / scientific supervisor A.B. Kitayev, O.V. Larchenko, - Perm: Perm state national research university, 2015. - p. 212-220.

4. Margaryan V.G. Assessment, management and regulation of the way of monthly runoff water season of Vedi river. Abstract book: "The international conference on regional climate CORDEX 2016", 17th - 20th May 2016, Aula Magna Stockholm University, Stokholm, Sweden. - P. 257.

5. Margaryan V.G. Estimation and Management of Annual Runoff of River Vedi. 7th International Water Resources Management Conference of ICWRS, 18-20 May 2016, Bochum, Germany, IWRM2016-17 